\title{
Laparoscopic Cerclage as a Treatment Option for Cervical Insufficiency
}

\section{Die laparoskopische Cerclage als Therapieoption bei Zervixinsuffizienz}

Authors

Affiliation
D. Bolla, L. Raio, S. Imboden, M. D. Mueller

Department of Obstetrics and Gynecology, University Hospital of Bern, Bern, Switzerland

\section{Key words}

- laparoscopic cerclage

- Goldfinger ${ }^{\circledR}$ device

- prematurity

- cervical insufficiency

- cervical cerclage

- transabdominal cerclage

Schlüsselwörter

- laparoskopische Cerclage

- Goldfinger ${ }^{\circledR}$-Gerät

- Frühgeburtlichkeit

- Zervixinsuffizienz

- zervikale Cerclage

- transabdominale Cerclage

$\begin{array}{ll}\text { received } & 2.2 .2015 \\ \text { revised } & 2.5 .2015 \\ \text { accepted } & 10.5 .2015\end{array}$

Bibliography

Dol http://dx.doi.org/

10.1055/s-0035-1557762

Geburtsh Frauenheilk 2015; 75 :

833-838 ๑ Georg Thieme

Verlag KG Stuttgart · New York ISSN 0016-5751

\section{Correspondence \\ Daniele Bolla, MD}

Department of Gynecology and Gynecologic Oncology

University of Bern

Inselspital

Effingerstrasse 102

3010 Bern

Switzerland

daniele.bolla@insel.ch

\section{Abstract \\ $\nabla$}

Background: The traditional surgical treatment for cervical insufficiency is vaginal placement of a cervical cerclage. However, in a small number of cases a vaginal approach is not possible. A transabdominal approach can become an option for these patients. Laparoscopic cervical cerclage is associated with good pregnancy outcomes but comes at the cost of a higher risk of serious surgical complications. The aim of the present study was to evaluate intraoperative and long-term pregnancy outcomes after laparoscopic cervical cerclage, performed either as an interval procedure or during early pregnancy, using a new device with a blunt grasper and a flexible tip.

Methods: All women who underwent laparoscopic cervical cerclage for cervical insufficiency in our institution using the Goldfinger ${ }^{\circledR}$ device (Ethicon Endo Surgery, Somerville, NJ, USA) between January 2008 and March 2014 were included in the study. Data were collected from the patients' medical records and included complications during and after the above-described procedure.

Results: Eighteen women were included in the study. Of these, six were pregnant at the time of laparoscopic cervical cerclage. Mean duration of surgery was $55 \pm 10$ minutes. No serious intraoperative or postoperative complications occurred. All patients were discharged at $2.6 \pm 0.9$ days after surgery. One pregnancy ended in a miscarriage at 12 weeks of gestation. All other pregnancies ended at term ( $>37$ weeks of gestation) with good perinatal and maternal outcomes.

Summary: Performing a laparoscopic cervical cerclage using a blunt grasper device with a flexible tip does not increase intraoperative complications, particularly in early pregnancy. We believe that use of this device, which is characterized by increased maneuverability, could be an important option to avoid intraoperative complications if

\section{Zusammenfassung \\ V}

Hintergrund: Die Therapie einer Zervixinsuffizienz besteht aktuell in der vaginalen Cerclage. In einigen wenigen Fällen ist dies nicht möglich, sodass die laparoskopische zervikale Cerclage eine Therapieoption sein kann, die aber mit einem höheren Risiko intraoperativer Komplikationen assoziiert ist. Das Ziel unserer Studie besteht darin, sowohl die intraoperative Sicherheit als auch die Langzeitergebnisse der mit einem „neuen“ Instrument durchgeführten laparoskopischen zervikalen Cerclage - präkonzeptionell oder in der Frühschwangerschaft durchgeführt - zu evaluieren. Methoden: Eingeschlossen wurden alle Frauen, bei denen zwischen Januar 2008 und März 2014 eine laparoskopische zervikale Cerclage mittels dem Goldfinger ${ }^{\circledR}$-Instrument (Ethicon Endo Surgery, Somerville, NJ, USA) aufgrund einer Zervixinsuffizienz durchgeführt wurde. Es wurden alle Daten der Patientinnen inklusive der peri- und postoperativen Komplikationen der oben beschriebenen Operationstechniken gesammelt.

Ergebnisse: Achtzehn Frauen wurden in unsere Studie eingeschlossen. Zum Zeitpunkt der durchgeführten laparoskopischen zervikalen Cerclage waren 6 Patientinnen schwanger. Die mittlere Operationsdauer betrug $55 \pm 10$ Minuten. Es traten keine ernsthaften peri- und postoperativen Komplikationen auf. Alle Patientinnen konnten nach 2,6 $\pm 0,9$ Tagen aus dem Spital entlassen werden. Bei einer Patientin kam es zu einem Abort in der 12. SSW. Bei allen anderen Schwangerschaften kam es zur Geburt am Termin (>37. SSW) mit gutem perinatalen und maternalen Outcome.

Zusammenfassung: Das Durchführen einer laparoskopischen zervikalen Cerclage mit diesem flexiblen Instrument scheint die intraoperative Komplikationsrate - insbesondere in der Frühschwangerschaft - nicht zu erhöhen. Die Verwendung des flexiblen und sehr gut manövrierbaren 
surgical access is limited due to the anatomical situation. However, because of the small sample size, further studies are needed to confirm our findings.
Instruments ist eine interessante Möglichkeit bei Patientinnen mit anatomisch schwierigen Verhältnissen und der Notwendigkeit einer zervikalen Cerclage. Um die guten Resultate zu bestätigen sind weitere Studien notwendig.

\section{Introduction}

\section{$\nabla$}

Cervical insufficiency $(\mathrm{CI})$ or incompetence is a well-known condition in obstetrics with an incidence of $0.1-1 \%$, and is notoriously associated with a high risk of second trimester abortion and/or preterm delivery [1]. The main problem of $\mathrm{Cl}$ is its diagnosis as it is not associated with specific symptoms and can only be postulated on the basis of the patient's obstetric history (e.g., silent cervical dilatation in a previous pregnancy or preterm delivery after cervical surgery).

A short or even absent cervix due to previous conization or cervical amputation significantly increases the risk of CI [2]. Such secondary forms of CI may be also boosted by the patient's decreased capacity to withstand ascending infectious agents because of reduced production of bacteriostatic cervical mucus [3]. Changes to the collagen structure due to reduced strength or content and defective collagen may be additional reasons for preterm delivery due to cervical incompetence [4].

The traditional surgical treatment for cervical insufficiency consists of vaginal placement of cervical stitches, known as transvaginal cervical cerclage (TVC). This method was first described by Lash and Lash in 1950 and subsequently established by Shirodkar in 1950 and McDonald in 1957 [4-6]. Compared to the outcomes if no treatment is done, prophylactic cervical cerclage reduces the incidence of preterm birth in selected women at risk of recurrent preterm delivery [1]. Recently, a non-surgical approach using pessaries has been proposed for women with sonographic short cervix; however, the results have been conflicting [7-8]. In a small number of cases, however, the vaginal approach is either not possible or very difficult [9]. To treat such patients Benson und Durfee developed the technique of transabdominal placement of cervical cerclage (TAC), first described in 1965 [10]. The advances in minimally invasive surgery have led to the increasing use of laparoscopy for abdominal cerclage placement. In 1998 Sciabetta et al. described the first laparoscopic approach for cerclage in non-pregnant women, and in the same year Lesser et al. described the same procedure performed during pregnancy [11-12]. Since then, different series of abdominal cerclage placements via laparotomy or laparoscopy have confirmed the high rate of pregnancy success, the reliability of the laparoscopic approach, and the similar risks of serious intraoperative complications [13-15].

The aim of the present study was to evaluate the surgical results and pregnancy outcomes after a novel technique for laparoscopic cervical cerclage performed either as an interval procedure or during early pregnancy.

\section{Material and Method}

$\nabla$

Between January 2008 and March 2014 a retrospective single cohort study was done of all women with a previous poor obstetric history who underwent laparoscopic abdominal cerclage (LAC) placement either prior to conception or during pregnancy using the Goldfinger ${ }^{\circledR}$ device (Ethicon Endo Surgery, Somerville, NJ, USA). The device has a blunt grasper and a flexible tip (BgFt de- vice) guided from the handle. Written informed consent after extensive counselling was obtained from all patients before performing LAC. All women were informed about the need for elective cesarean section.

\section{Inclusion criteria}

Inclusion criteria were women with prior failed TVC (causing fetal loss or premature delivery in the second or third trimester) and patients in whom vaginal insertion was technically difficult or impossible due to an extremely short or absent cervix.

\section{Data collection}

Data were collected from the patients' medical records and included complications during and after the procedure. A telephone interview was also conducted with all patients and included pregnancy outcome and physical complaints after the procedure. The follow-up period varied from 1 to 65 months. Ethical approval for the current study was obtained from the local institutional review board (Ethics Committee of the Canton of Bern, Switzerland).

\section{Surgical technique}

LAC was performed under general anesthesia by a single operator according to the standard surgical and perioperative protocol of our hospital. Endocervical swabs for chlamydia and mycoplasma were obtained preoperatively to exclude cervical infection. In pregnant patients an abdominal sonography was performed preoperatively to confirm fetal vitality and gestational age. Prophylactic antibiotic treatment was administered (amoxicillin $2000 \mathrm{mg}$ and clavulanic acid $200 \mathrm{mg}$ ). Tocolysis with indomethacin was performed for $48 \mathrm{~h}$ in pregnant women, starting the evening before surgery, and no uterine manipulator was used. In non-pregnant women a RUMI uterine manipulator or a Hegar size 8 was inserted to mobilize the uterus. All patients underwent laparoscopy using the Veress technique to create a pneumoperitoneum with an intraabdominal pressure of $10 \mathrm{mmHg}$. A 10 -mm optical trocar was placed in the navel and a $30^{\circ}$ scope was used during all procedures. Two 5-mm trocars were placed under direct visual control laterally in each lower quadrant and one 12$\mathrm{mm}$ trocar was placed suprapubically in the midline. After checking the abdominal cavity, the intraabdominal procedure was started by opening the plica uterovesicalis with a bipolar hook. The vesico-cervical space was identified after partial atraumatic mobilization of the bladder. The peritoneal opening was extended laterally until the uterine artery could be identified on both sides. A 5-mm Mersilene tape (Ethicon, Somerville, NJ, USA) with detached needles was then introduced into the abdomen and placed in the pouch of Douglas. The BgFt device, which consisted of a 5-mm laparoscopic grasper with a flexible tip guided from the handle ( $\bullet$ Fig. 1), was introduced through the suprapubic trocar in an anterior-to-posterior direction, continued through the right broad ligament in the avascular space medially from the uterine artery until its tip appeared above the uterosacral ligament ( $\bullet$ Fig. 2 ). The peritoneum was then incised directly over the BgFt device using a Mahnes grasper, the Mersilene tape was slipped into the tip of the BgFt device, retracted 


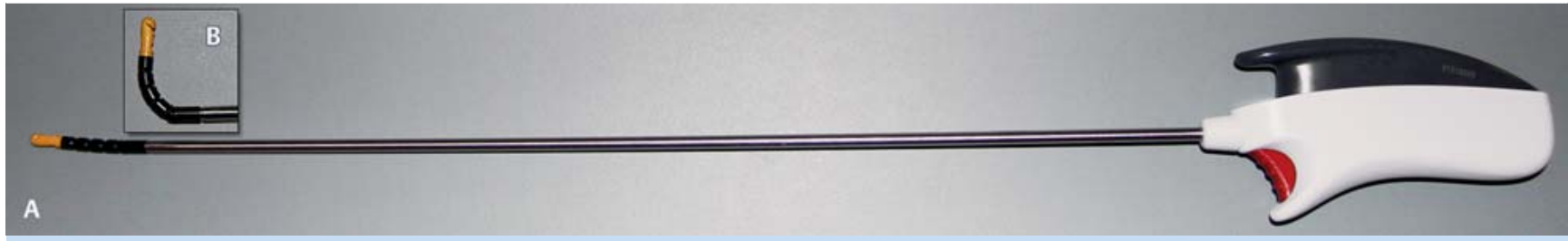

Fig. 1 A Laparoscopic device with a blunt grasper and a flexible tip guided from the handle (Goldfinger ${ }^{\circledR}$ device); B Flexible tip of the blunt grasper.

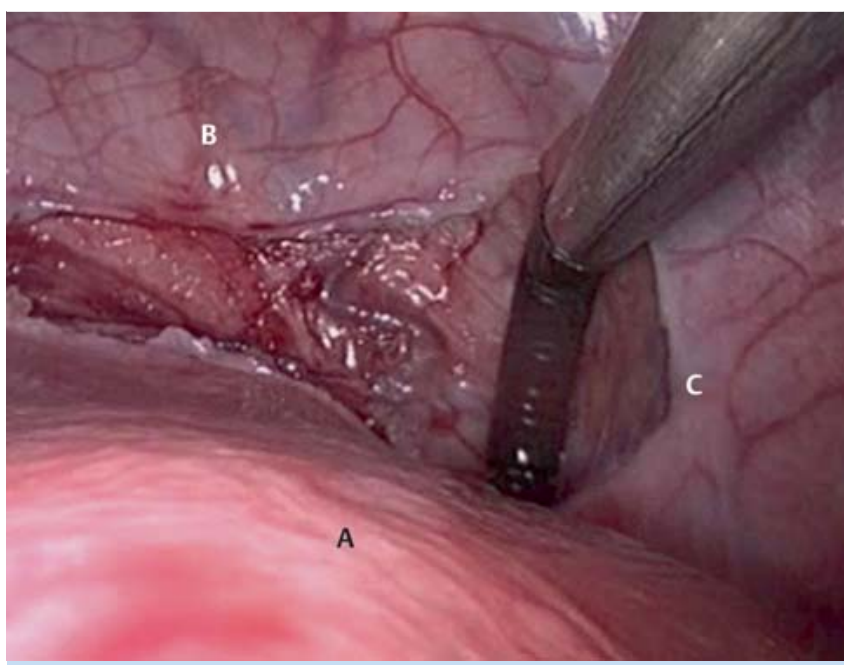

Fig. 2 Surgical steps of laparoscopic abdominal cerclage: laparoscopic introduction of the blunt grasper device with a flexible tip in an anterior-toposterior direction through the right broad ligament in the avascular space medially from the uterine artery. $\mathbf{A}=$ uterus, $\mathbf{B}=$ bladder, $\mathbf{C}=$ Goldfinger $^{\circledR}$ device.

( Fig. 3), and a tunnel was created by simple backward retraction of the BgFt device ( Fig. 4). The same procedure was performed contralaterally. Direct visualization of the posterior face of the broad ligaments and of the uterosacral ligament in the pregnant uterus was possible with the $30^{\circ}$ scope and smooth, atraumatic mobilization of the uterus; in non-pregnant women mobilization of the uterus was achieved using a RUMI manipulator. After checking the correct placement of the tape medially from the uterine artery and far away from the ureter, the tape was firmly knotted five times anteriorly at the cervicoisthmic junction. The procedure ended with peritonization above the knot of the plica uterovesicalis. All pregnant women underwent

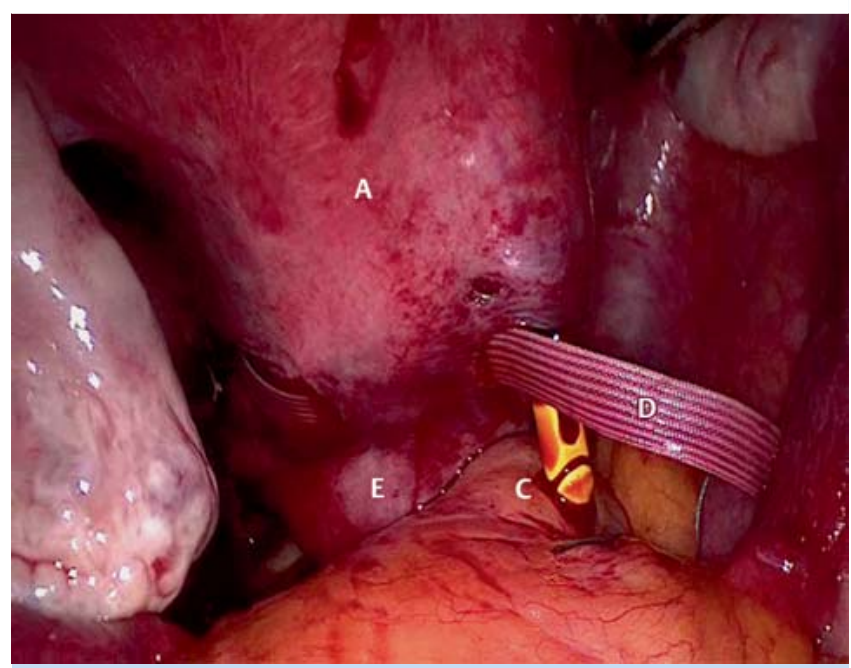

Fig. 3 Surgical steps of laparoscopic abdominal cerclage: the Mersilene tape is slipped into the tip of the blunt grasper device and retracted in a posterior-to-anterior direction. $\mathbf{A}=$ uterus, $\mathbf{C}=$ Goldfinger $^{\circledR}$ device,

$\mathbf{D}=$ Mersilene tape, $\mathbf{E}=$ pouch of Douglas.

transvaginal ultrasound to check embryo vitality, with Doppler imaging of the uterine artery and to check the absence of hydronephrosis before discharge. An elective cesarean section was planned at 39 weeks of gestation.

\section{Outcome measures}

The primary outcomes were defined as pregnancy outcome, incidence of preterm delivery at $<34$ weeks of gestation, and neonatal outcome.

Secondary outcomes were defined as surgical outcome parameters using the BgFt device, including total blood loss, perioperative complications, and duration of hospitalization.
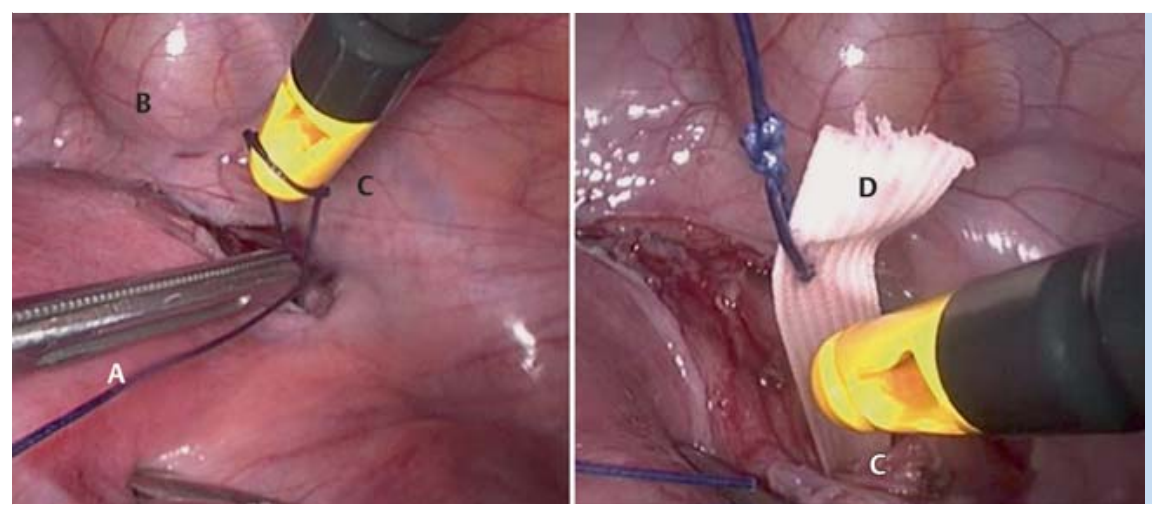

Fig. 4 Surgical steps of laparoscopic abdominal cerclage: retraction of the Mersilene tape in a posterior-to-anterior direction through the blunt grasper device.

A $=$ uterus,

B $=$ bladder,

$\mathbf{C}=$ Goldfinger ${ }^{\circledR}$ device,

D = Mersilene tape. 
Table 1 Clinical characteristics of the study population.

\begin{tabular}{lc} 
Characteristics & Results \\
Maternal age, years (mean \pm SD) & $33 \pm 4$ \\
\hline Gravidity (mean \pm SD) & $4 \pm 0.8$ \\
\hline Nullipara (n) & 9 \\
\hline Patients with previous term pregnancy $(\mathrm{n})$ & 4 \\
\hline Adverse obstetric history $(\mathrm{n})$ & \\
- early miscarriage & 17 \\
- late miscarriage & 30 \\
\hline prior failed TVC & 6 \\
\hline prior cervical surgery (cone, LEEP) & 2 \\
\hline ectopic pregnancy (n) & 2 \\
- preterm delivery & 2 \\
Gestational age at intervention, weeks (mean \pm SD) & $11.4 \pm 1.6$
\end{tabular}

TVC = transvaginal cerclage; LEEP = loop electrosurgical excision procedure; $\mathrm{n}=$ number

\section{Results}

$\nabla$

\section{Clinical characteristics}

A total of eighteen women were included in our study. The mean age of the women was $33 \pm 4$ years. At surgery, six of 18 women (group 1) were pregnant (mean week of gestation: 11.4 \pm 1.6 ); 12 women underwent surgery as an interval procedure (group 2). In the pregnant group, one woman presented with a twin pregnancy. All patients had had previous second trimester pregnancy loss or preterm delivery. The clinical characteristics of the study population are summarized in 0 Table 1 .

\section{Surgical outcome}

The mean duration of surgery was $55 \pm 10$ minutes. The blood loss in all cases was minimal $(<20 \mathrm{ml})$. No serious intraoperative or perioperative complications occurred, and no cases required conversion to laparotomy. All patients (group 1 and group 2) were discharged by $2.6 \pm 0.9$ days after surgery. In one case, an additional TVC was performed in early pregnancy because of bulging of the membranes through the cervical channel after LAC due to insufficient tightening of the tape. Unfortunately, this pregnancy ended in a miscarriage at 12 weeks of gestation. All the other women still have the tape without any symptoms or pelvic infection up to 65 months after the initial surgery.

\section{Pregnancy outcome}

The mean gestational age at delivery for all pregnancies (groups 1 and 2) was $37.3 \pm 1.9$ weeks of gestation, with an overall pregnancy success of $95 \%$. All women in group 1 with one exception (6/18) had an uncomplicated pregnancy course and were delivered by cesarean section at a mean of $37 \pm 1.9$ weeks of gestation with good neonatal outcomes. This group included also a twin pregnancy. In group 2, 7/12 became pregnant at a mean time after intervention of $2 \pm 0.5$ months and $4 / 12$ are still not pregnant (three of them recently underwent surgery). The women in group 2 who became pregnant had an uncomplicated course and were delivered by cesarean section at $38 \pm 0.7$ weeks of gestation without problems and with good neonatal outcomes. No neonatal death occurred in either of the groups, and no baby had to be transferred to a neonatal intensive care unit. Additionately, four women (two of each group) became pregnant a second time, and in all these cases the pregnancy course, delivery and neonatal outcome were uncomplicated. Details of pregnancy outcomes are summarized in $\odot$ Table 2 . All patients stated that they would be
Table 2 Outcomes of the study population.

\begin{tabular}{|c|c|}
\hline Characteristics & Results \\
\hline Intraoperative complications ( $\mathrm{n})^{*}$ & 0 \\
\hline Estimated blood loss (ml) & $<20$ \\
\hline Operating time, minutes (mean \pm SD) & $55 \pm 10$ \\
\hline Mean hospital stay, days (mean \pm SD) & $2.6 \pm 0.9$ \\
\hline \multicolumn{2}{|l|}{ Pregnancy outcome (n) } \\
\hline first trimester spontaneous abortion & 1 \\
\hline preterm delivery (<34 weeks) & 0 \\
\hline - GA at delivery, weeks (mean \pm SD) & $37.3 \pm 1.9$ \\
\hline Overall pregnancy success** (>14 GA, \%) & 100 \\
\hline neonatal death $(\mathrm{n})$ & 0 \\
\hline transfer to NICU (n) & 0 \\
\hline
\end{tabular}

willing to undergo this surgery again, even though cesarean delivery is then required.

\section{Discussion}

There is currently no established classical or gold standard for laparoscopic abdominal cerclage (LAC). In the last 20 years laparoscopy has revolutionized the field of open surgery with benefits that include a reduction in postoperative pain, fewer complications and more rapid recovery. Only a few studies have compared the use of LAC with TAC, and although the use of laparoscopy was considered superior for the above-described reasons and because pregnancy outcomes were similar, the same rates of intraoperative complications were observed [13-15]. In general, the goal of this intervention is the placement of a tape medially from the uterine artery and above the sacrouterine ligaments. Different methods have been used for this. Approaches include using a large needle attached to the Mersilene tape, Prolene suture (Ethicon Endo Surgery, Somerville, NJ, USA) [14,16-18] or another polyester tape (B. Braun Medical AG, Sempach, Switzerland) [19], using the transabdominal Endoclose suture carrier $[13,20-21]$, piercing through the lateral side of the cervix, and non-sharp tunneling through the broad ligament using standard laparoscopic instruments [22-23]. However, if the anatomy is changed due to pregnancy, these techniques can become very challenging, particularly because of the increased size of the uterus and the impossibility of using a uterine manipulator.

For this reason, we decided to use a new device (BgFt) which is characterized by a flexible tip and a blunt end that allows for an easier passage between structures, reducing the risk of damage to adjacent structures. The BgFt device was originally designed for the placement of laparoscopic gastric bands and because of its flexibility has also been used successfully to perform other surgical operations such as distal pancreatectomy [24].

We found that the BgFt device allowed us to perform non-sharp tunneling through the broad ligament in an avascular space following the anatomical curve of the uterus and to place the cerclage tape correctly and precisely, reducing the risk of accidental injury. Our current study confirms this; in all cases surgery was completed without intraoperative complications. A good visualization of the vessels is essential in LAC, which in our opinion can be guaranteed by using an anterior-posterior approach starting with the opening of the plica uterovesicalis, continuing 

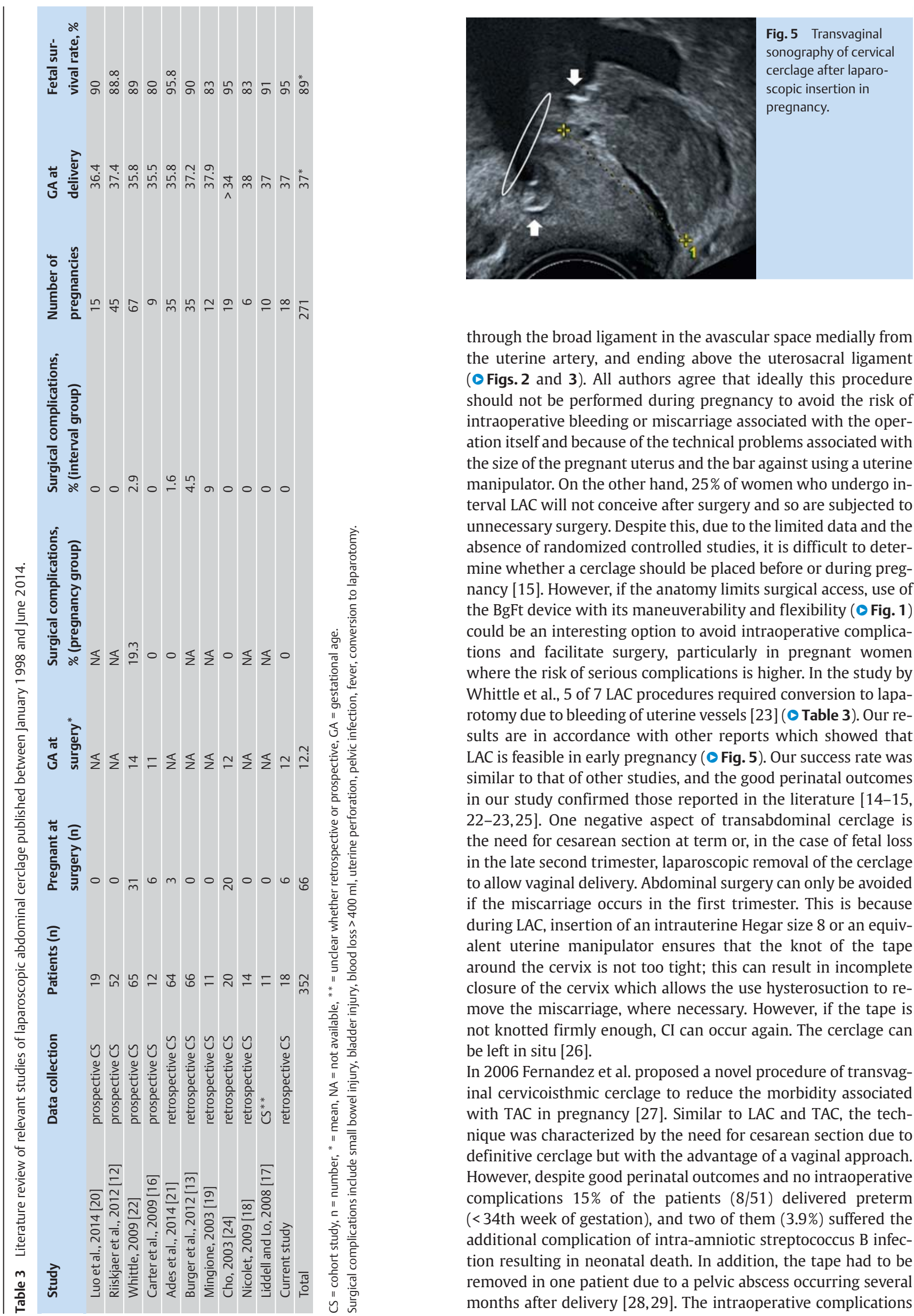

through the broad ligament in the avascular space medially from the uterine artery, and ending above the uterosacral ligament ( Figs. 2 and 3). All authors agree that ideally this procedure should not be performed during pregnancy to avoid the risk of intraoperative bleeding or miscarriage associated with the operation itself and because of the technical problems associated with the size of the pregnant uterus and the bar against using a uterine manipulator. On the other hand, $25 \%$ of women who undergo interval LAC will not conceive after surgery and so are subjected to unnecessary surgery. Despite this, due to the limited data and the absence of randomized controlled studies, it is difficult to determine whether a cerclage should be placed before or during pregnancy [15]. However, if the anatomy limits surgical access, use of the BgFt device with its maneuverability and flexibility (๑ Fig. 1) could be an interesting option to avoid intraoperative complications and facilitate surgery, particularly in pregnant women where the risk of serious complications is higher. In the study by Whittle et al., 5 of 7 LAC procedures required conversion to laparotomy due to bleeding of uterine vessels [23] ( $\triangle$ Table 3). Our results are in accordance with other reports which showed that LAC is feasible in early pregnancy ( $\bullet$ Fig. 5). Our success rate was similar to that of other studies, and the good perinatal outcomes in our study confirmed those reported in the literature [14-15, $22-23,25]$. One negative aspect of transabdominal cerclage is the need for cesarean section at term or, in the case of fetal loss in the late second trimester, laparoscopic removal of the cerclage to allow vaginal delivery. Abdominal surgery can only be avoided if the miscarriage occurs in the first trimester. This is because during LAC, insertion of an intrauterine Hegar size 8 or an equivalent uterine manipulator ensures that the knot of the tape around the cervix is not too tight; this can result in incomplete closure of the cervix which allows the use hysterosuction to remove the miscarriage, where necessary. However, if the tape is not knotted firmly enough, $\mathrm{CI}$ can occur again. The cerclage can be left in situ [26].

In 2006 Fernandez et al. proposed a novel procedure of transvaginal cervicoisthmic cerclage to reduce the morbidity associated with TAC in pregnancy [27]. Similar to LAC and TAC, the technique was characterized by the need for cesarean section due to definitive cerclage but with the advantage of a vaginal approach. However, despite good perinatal outcomes and no intraoperative complications $15 \%$ of the patients $(8 / 51)$ delivered preterm ( $<34$ th week of gestation), and two of them (3.9\%) suffered the additional complication of intra-amniotic streptococcus B infection resulting in neonatal death. In addition, the tape had to be removed in one patient due to a pelvic abscess occurring several months after delivery $[28,29]$. The intraoperative complications 
in the present study were as low as those reported for transvaginal cervicoisthmic cerclage procedure, but the pregnancy outcomes in our study were better. With the exception of one patient (cerclage removed after a miscarriage at 12 weeks of gestation), all patients interviewed in our cohort reported no problems during or after pregnancy. Four of the 13 women who were pregnant at LAC or became pregnant subsequently went on to have a second, spontaneous pregnancy; the second pregnancy also passed without complications and the neonatal outcome was good in all cases.

Limitations of the present study are the low level of scientific evidence due to the retrospective design of the study, the small sample size, and the lack of a control group. However, our results show interesting outcome measures.

\section{Conclusions}

This new technique for LAC seems to be a promising option for the treatment of $\mathrm{CI}$ in women with a poor obstetric history. Our initial experience demonstrated good obstetric results with no perioperative complications. This technique could be particularly useful if performed during early pregnancy where the increased maneuverability and flexibility of the device permits better surgical access. However, our results should be viewed with caution due to the limited number of cases and the study design.

\section{Conflict of Interest}

$\nabla$

Dr. Daniele Bolla, Prof. Luigi Raio, Dr. Sara Imboden and Prof. Michael D. Mueller have no conflicts of interest in connection with this article, in particular no conflicts of interest in connection with the Goldfinger ${ }^{\circledR}$ device (Ethicon Endo Surgery, Somerville, $\mathrm{NJ}$, USA) or with any of the materials used in surgery.

\section{References}

1 Alfirevic Z, Stampalija T, Roberts $D$ et al. Cervical stitch (cerclage) for preventing preterm birth in singleton pregnancy. Cochrane Database Syst Rev 2012; 4: CD008991

2 Raio L, Ghezzi F, Di Naro E et al. Duration of pregnancy after carbon dioxide laser conization of the cervix: influence of cone height. Obstet Gynecol 1997; 90: 978-982

3 Becher N, Hein M, Danielsen CC et al. Matrix metalloproteinases in the cervical mucus plug in relation to gestational age, plug compartment, and preterm labor. Reprod Biol Endocrinol 2010; 8: 113

4 Petersen LK, Uldbjerg N. Cervical collagen in non-pregnant women with previous cervical incompetence. Eur J Obstet Gynecol Reprod Biol 1996; 67: 41-45

5 Lash AF, Lash SR. Habitual abortion: the incompetent internal os of the cervix. Am J Obstet Gynecol 1950; 59: 68-76

6 Shirodkar VN. A new method of operative treatment for habitual abortions in the second trimester of pregnancy. Antiseptic 1955; 52: 299300

7 Kyvernitakis I, Khatib R, Stricker $N$ et al. Is early treatment with a cervical pessary an option in patients with a history of surgical conisation and a short cervix? Geburtsh Frauenheilk 2014; 74: 1003-1008
8 Kypros Nicolaides, King's College Hospital London. Randomized study of pessary versus standard management in women with increased chance of premature birth. Oral presentation. FMF Congress Nizza, 2014

9 McDonald IA. Suture of the cervix for inevitable miscarriage. J Obstet Gynaecol Br Commonw 1957; 64: 346-353

10 Harger JH. Cerclage and cervical insufficiency: an evidence-based analysis. Obstet Gynecol 2002; 100: 1313-1327; Erratum in: Obstet Gynecol 2003; 101: 205

11 Benson RC, Durfee RB. Transabdominal cervicouterine cerclage during pregnancy for the treatment of cervical incompetency. Obstet Gynecol 1965; 25: 145-155

12 Scibetta JJ, Sanko SR, Phipps WR. Laparoscopic transabdominal cervicoisthmic cerclage. Fertil Steril 1998; 69: 161-163

13 Lesser KB, Childers JM, Surwit EA. Transabdominal cerclage: a laparoscopic approach. Obstet Gynecol 1998; 91 (5 Pt 2): 855-856

14 Riiskjaer $M$, Petersen $O B$, Uldbjerg $N$ et al. Feasibility and clinical effects of laparoscopic abdominal cerclage: an observational study. Acta Obstet Gynecol Scand 2012; 91: 1314-1318

15 Burger NB, Einarsson JI, Brölmann HA et al. Preconceptional laparoscopic abdominal cerclage: a multicenter cohort study. Am J Obstet Gynecol 2012; 207: 273.e1-273.e12

16 Burger NB, Brölmann HA, Einarsson JI et al. Effectiveness of abdominal cerclage placed via laparotomy or laparoscopy: systematic review. J Minim Invasive Gynecol 2011; 18: 696-704

17 Ghomi A, Rodgers B. Laparoscopic abdominal cerclage during pregnancy: A case report and a review of the described operative techniques. J Minim Invasive Gynecol 2006; 13: 337-341

18 Carter JF, Soper DE, Goetzl LM et al. Abdominal cerclage for the treatment of recurrent cervical insufficiency: laparoscopy or laparotomy? Am J Obstet Gynecol 2009; 201: 111.e1-111.e4

19 Liddell HS, Lo C. Laparoscopic cervical cerclage: a series in women with a history of second trimester miscarriage. J Minim Invasive Gynecol 2008; 15: 342-345

20 Nicolet G, Cohen M, Begue L et al. Laparoscopic cervico-isthmic cerclage evaluation. Gynecol Obstet Fertil 2009; 37: 294-299

21 Mingione MJ, Scibetta JJ, Sanko SR et al. Clinical outcomes following interval laparoscopic transabdominal cervico-isthmic cerclage placement: case series. Hum Reprod 2003; 18: 1716-1719

22 Luo L, Chen SQ Jiang HY et al. Successful treatment of cervical incompetence using a modified laparoscopic cervical cerclage technique: a cohort study. Eur J Obstet Gynecol Reprod Biol 2014; 179 C: 125-129

23 Ades A, May J, Cade TJ et al. Laparoscopic transabdominal cervical cerclage: a 6-year experience. Aust N Z J Obstet Gynaecol 2014; 54: 117120

24 Whittle WL, Singh SS, Allen L et al. Laparoscopic cervico-isthmic cerclage: surgical technique and obstetric outcomes. Am J Obstet Gynecol 2009; 201: 364.e1-364.e7

25 Robinson SM, White SA. The use of Goldfinger(TM)(Ethicon Endo Surgery) to facilitate laparoscopic distal pancreatectomy. Ann R Coll Surg Engl 2009; 91: 524-525

26 Cho CH, Kim TH, Kwon SH et al. Laparoscopic transabdominal cervicoisthmic cerclage during pregnancy. J Am Assoc Gynecol Laparosc 2003; 10: 363-366

27 Agdi M, Tulandi T. Placement and removal of abdominal cerclage by laparoscopy. Reprod Biomed Online 2008; 16: 308-310

28 Deffieux X, de Tayrac R, Louafi $N$ et al. Transvaginal cervico-isthmic cerclage using polypropylene tape: surgical procedure and pregnancy outcome: Fernandez's procedure. J Gynecol Obstet Biol Reprod (Paris) 2006; 35 (5 Pt 1): 465-471

29 Deffieux X, Faivre E, Senat MV et al. Transvaginal cervicoisthmic cerclage using a polypropylene sling: pregnancy outcome. J Obstet Gynaecol Res 2011; 37: 1297-1302 